\title{
Biomass and Lipid Yield of Locally Isolated Microalgae
}

\author{
L. D. B. Ngoc, M. F. Adenan, B. A. Bato, N. Mansor, and S. Mahadzir
}

\begin{abstract}
Microalgae are known as a potential feedstock for bio-energy production. However not all strains of microalgae can be used to produce lipid. It depends on their lipid content. This study therefore focuses on locally isolated microalgae to determine their potential in lipid production. The freshwater samples were extracted from various locations in Malaysia. After classification, a locally isolated strain referred to as BA due to its similar characteristics as the Botrydiopsisarrhiza species is chosen for comparison with commercial microalgae Chlorella Fusca (CF) about the growth and lipid content. Besides that, although the results show that $C F$ has higher lipid content than $B A$ strain, BA has higher yield of biomass than $C F$. The shape of the curve is almost the same and the difference is not so much. It means that the BA strain has a potential in lipid production as well
\end{abstract}

Index Terms-Botrydiopsisarrhiza, chlorella fusca, lipid production, microalgae, local microalgae

\section{INTRODUCTION}

Microalgae are currently being promoted as an ideal next generation bio-energy feedstock because they do not compete with food or feed crops, can potentially produce much higher areal oil yields than current agricultural crops, and can be produced on barren land. Microalgae have broad bio-energy potential as they can be used to produce liquid transportation and heating fuels, such as biodiesel and ethanol, or anaerobically digested to produce biogas. The use of microalgae as bio-energy feedstock seems to be promising mainly due to: [1]

1) Biomass doubling times in microalgae during exponential growth are commonly as short as $3.5 \mathrm{~h}$. Due to their simple cellular structure, microalgae have higher rates of biomass and oil production than conventional crops. Oil content in microalgae can exceed $80 \%$ by weight of dry biomass. Can be harvested batch-wise nearly all-year-around providing a reliable and continuous supply of oil. Microalgae can produce $30-100$ times more energy per hectare as compared to terrestrial crops.

2) Salty or waste water can be used for the culture of algae. Atmospheric carbon dioxide is the source of carbon for the growth of algae.

3) Their lipid content in microalgae could be adjusted through altering growth media composition. Depending on species of algae, can produce many kinds of lipids, hydrocarbons and other complex oils.

4) The production of biofuel from microalgae can be coupled with flue gas $\mathrm{CO} 2$ mitigation, waste water

Manuscript received April 10, 2013;revised June 3, 2013.This work was supported in part by the UniversitiTeknologiPetronas.

L. D. B. Ngocis with the Chemical Engineering Department, UniversitiTeknologi PETRONAS, Malaysia(e-mail n_1190605@yahoo.com.vn). treatment and production of high value chemicals.

Through the process of photosynthesis, microalgae convert water, carbon dioxide and light into oxygen and biomass. At the end of the process, according to the characteristics of the micro-algal biomass obtained, it can be used to produce biodiesel, ethanol, hydrogen, biogas or direct burning and are not precursors of problems caused by fossil fuels and renewable energies [2], [3]. Nowadays, there are two kinds of cultivation systems: open pond and closed photo-bioreactors system. Closed photo-bioreactors system has more efficiency but it cannot be applied in industry because its high cost. Until now, transesterification is the common way to produce biodiesel from the oil of algae. The transesterification reaction uses super critical fluids, enzymatic, acid-catalysed or alkali-catalysed[2], [4]

\section{BACKGROUND}

Wenguang et al. collected 60 algae-like microorganisms from different sampling sites in Minnesota to select high-lipid producing facultative heterotrophic microalgae strains capable of growing on concentrated municipal wastewater (CMW) for simultaneous energy crop production and waste water treatment. Among twenty- seven strains were found, 5 strains has the ability to adapt to CMW, high growth rates $\left(0.455-0.498 \mathrm{~d}^{-1}\right)$ and higher lipid productivities (74.5-77.8 $\left.\mathrm{mgL}^{-1} \mathrm{~d}^{-1}\right)$ [5]. Brian et al also found out wild microalgae which are isolated from Minnesota lakes and ponds have high productivity and sufficient lipids for further use in biodiesel production studies when comparing with D.tertiolecta[6]. Microalgae is the photosynthesis organism, $\mathrm{CO}_{2}$ supplying during the growth is very important especially the concentration. There are many studies researched about $\mathrm{CO}_{2}$ concentration. With chlorella sp. the suitable range of $\mathrm{CO}_{2}$ concentration is $0.33-15 \%$ [7].

Most of the microalgae in past studies about bio-fuel are commercial microalgae which focus more on their potential. Some studies on locally isolated microalgae found out that local microalgae also have a potential to produce lipid as a feedstock for bio-fuel, but none of them study about the local microalgae in Malaysia.

Microalgae used in this study will be extracted from various locations in Malaysia such as river, pond. The locally microalgae need to be classified before study about the local algae's potential. Depending on problem statement, the objective of this study is identification the potential of locally isolated microalgae in lipid production depending on the yield of biomass and lipid content.

\section{Methodology}

\section{A. Sampling}

The local microalgae used in this study are extracted from 
marine and freshwater samples. The sampling location and categories are as listed in Table I. Samples were taken at $1-5$ $\mathrm{m}$ from the coastline at approximately $10-20 \mathrm{~cm}$ depth. Sample S5 however was taken approximately $10 \mathrm{~m}$ from the coastline and at $50 \mathrm{~cm}$ depth. All samples were kept in clear plastic bottles to provide clear constant sunlight and transported to the laboratory.

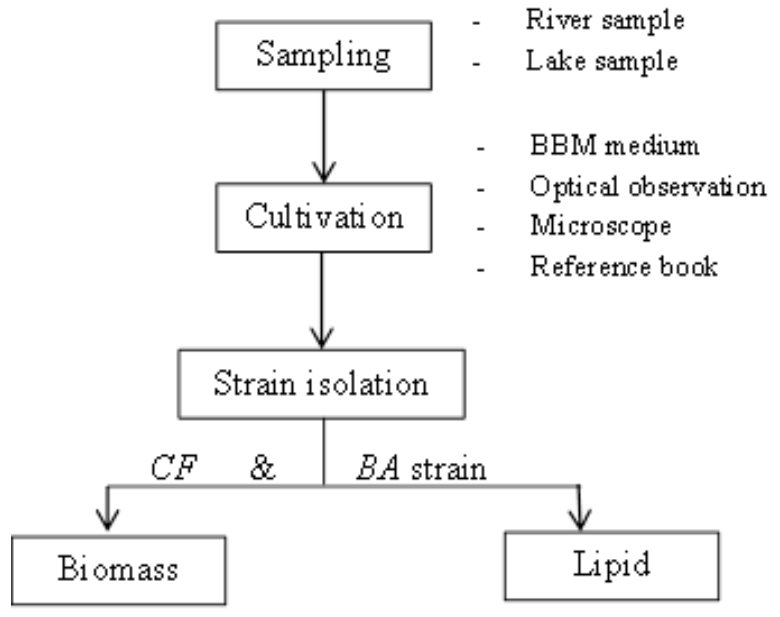

Fig. 1.Methodology

TABLE I: SAMPLING LOCATION AND CATEGORY

\begin{tabular}{|l|c|c|c|}
\hline & \multicolumn{3}{|c|}{ Fresh Water Sa mples } \\
\hline & $\begin{array}{c}\text { Lake in } \\
\text { front of } \\
\text { UTP }\end{array}$ & $\begin{array}{c}\text { Lake at UTP } \\
\text { Mosque }\end{array}$ & $\begin{array}{c}\text { Perak } \\
\text { River }\end{array}$ \\
\hline Sample & 1 & 2 & 3 \\
\hline $\begin{array}{l}\text { From the } \\
\text { Edge of beach }\end{array}$ & & $1-5 \mathrm{~m}$ \\
\hline Depth & \multicolumn{3}{|c|}{$10-20 \mathrm{~cm}$} \\
\hline
\end{tabular}

\section{B. Experiment}

\section{1) Classification}

All of the samples were placed in $80 \mathrm{ml}$ of BBM medium in $1 \mathrm{~L}$ conical flasks to identify its suitable for growth using this medium. The fresh water samples were placed in BBM 1 medium which contains $1 \mathrm{ml}$ of BBM in 1 liter solution. Oncemicroalgae shows positive growth (identified visually by bright green residues), microscopic identification using MEIJI microscope is done at $100 \mathrm{X}$ magnification. Themicroscope images of the microalgae are compared to the reference based on its morphological characteristics. After identification, the samples will be inoculated in agar medium in petri dishes for separation. The colony in petri dishes must be of the colony before it is inoculated to liquid medium in test tube for growth and the original samples. After get a pure strains, one strain (BotrydiopsisArrhiza $(B A)$ ) is chosen to growth in the tanks with the light and air are supplied continuously (pH:7-8, temperature: $23-24^{0} \mathrm{C}$, intensity: 13000 lux, air flow: $4.8 \mathrm{~m}^{3} / \mathrm{h}$ ).

\section{2) Lipid production}

During the cultivation, the biomass are weighted every day.
The lipid content applied Bligh and Dyer method done every 2 days. Comparing the yield of biomass and lipid content between $B A$ and Chlorella fusca $(C F)$, the potential of locally isolated microalgae $(B A)$ in lipid production is determined.

\section{RESUlts AND Discussion}

\section{A. Experiment}

\section{1) Classification}

Microscope observation with the objective lenses at 100X shows that there are single cells containing green colored components. This could indicate presence of chlorophyll, thus identifying the single cells as algae. Observation after 6 days, the sample growth in BBM medium became greener than the sample in the first day. This indicates that the microalgae are cultivating well. Microscope observation with objective lenses at 100X Magnification found various types of microalgae strain. Most are green, yellow-green or golden in colors. Photos of each strain were obtained and classified based on its characteristic as stated by John et al (2003)[8].The classification was as shown in Table II.

TABLE II: CLASSIFICATION

\begin{tabular}{|c|l|c|c|c|}
\hline No & \multicolumn{1}{|c|}{ Strains } & $\begin{array}{c}\text { Sample } \\
\mathbf{1} \\
(\mathbf{6 7 \%})\end{array}$ & $\begin{array}{c}\text { Sample 2 } \\
\mathbf{( 4 4 \% )}\end{array}$ & $\begin{array}{c}\text { Sample 3 } \\
\mathbf{( 7 8 \% )}\end{array}$ \\
\hline 1 & ChlorolobionBraunii & $\sqrt{ }$ & & \\
\hline 2 & VaucheriaDichotoma & $\sqrt{ }$ & & \\
\hline 3 & ScenedesmusAcuminatus & & & $\sqrt{ }$ \\
\hline 4 & OphiocytiumParvulum & & & $\sqrt{ }$ \\
\hline 5 & OchromonasVariabilis & & & $\sqrt{ }$ \\
\hline 6 & Polyedriella Helvetica & $\sqrt{ }$ & $\sqrt{ }$ & $\sqrt{ }$ \\
\hline 7 & Stichococcusbacillaris & $\sqrt{ }$ & $\sqrt{ }$ & $\sqrt{ }$ \\
\hline 8 & Gloeobotryslimneticus & $\sqrt{ }$ & $\sqrt{ }$ & $\sqrt{ }$ \\
\hline 9 & BotrydiopsisArrhiza & $\sqrt{ }$ & $\sqrt{ }$ & \\
\hline
\end{tabular}

Based on the results, the microalgae communities in Sample 3 which was Perak River has the largest number of microalgae strains. It is because of the different conditions between river, lake and pond. The currents in river and lake may be the main reason for the dissimilarity as it affects the size and nutrition of the habitat. The currents in the river are stronger and more frequent than the lake. The pond does not have any current and the volume of the pond is the smallest amongst the samples. The nutrition available in the pond is less compared to the other habitats. Therefore, the number of differ strain are less.

\section{2) Lipid production}

The biomass accumulated by both strains was shown in Fig 3 as well as the lipid extracted by the Bligh and Dyer method was shown in Fig 4. Based on the data, the biomass of BA strain was higher than CF strain about $0.03 \mathrm{~g} / \mathrm{l}$ (about $9.68 \%$ ) on the harvesting day at Day 8. This shows that BA has potential in producing high biomass under conditions 
with solely air compared with the commercial CF strain. The total biomass at Day 10 shows higher performance by BA however the growth trend from Day 1 displays similarity between the two strains. Both reach a steady state by Day 8 . Although the biomass of BA strain under this condition was slightly higher than $\mathrm{CF}$, the lipid yield of $\mathrm{CF}$ was higher than
BA strain of about $10.7 \%$ at Day 8 . This maybe because the lipid yield was depended on the microalgae strain. In spite of CF has more lipid content than BA, the BA strain still has the potential in lipid production as the difference was only slightly and the trend shown in both strains are similar throughout the period of cultivation.

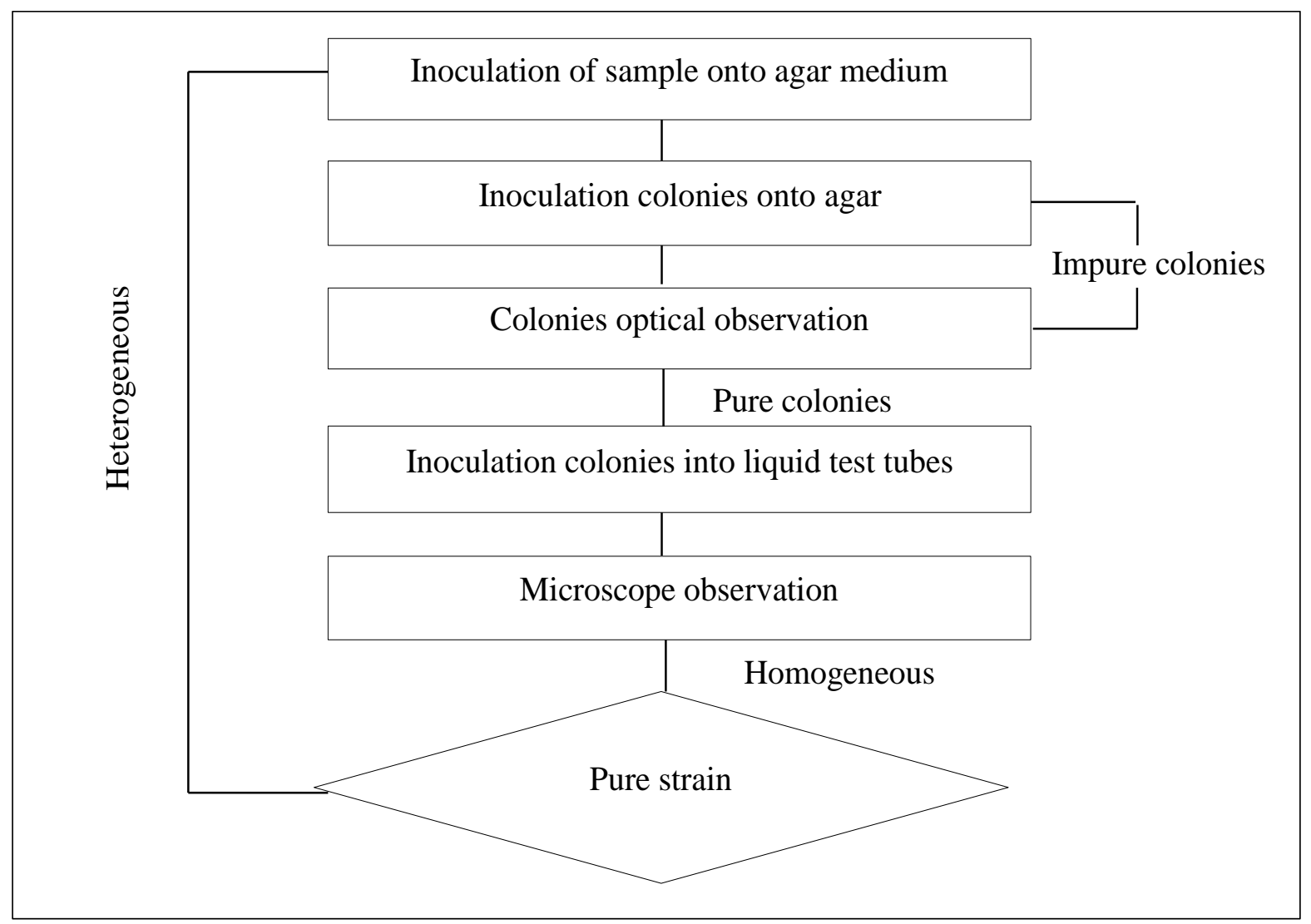

Fig. 2. Strain inoculation

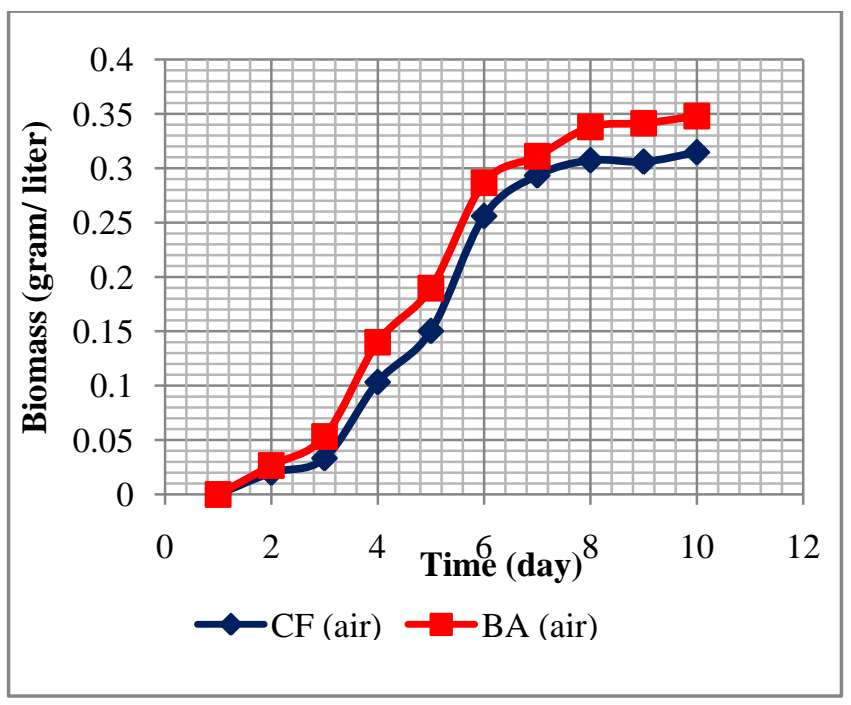

Fig. 3. Biomass

\section{CONCLUSION}

The samples after 6 days are greener than the first day. This could indicate that there may be microalgae in the samples. By comparison of the shape and monitor the characterization of organisms using reference book, there are 9 strains of microalgae in the samples.

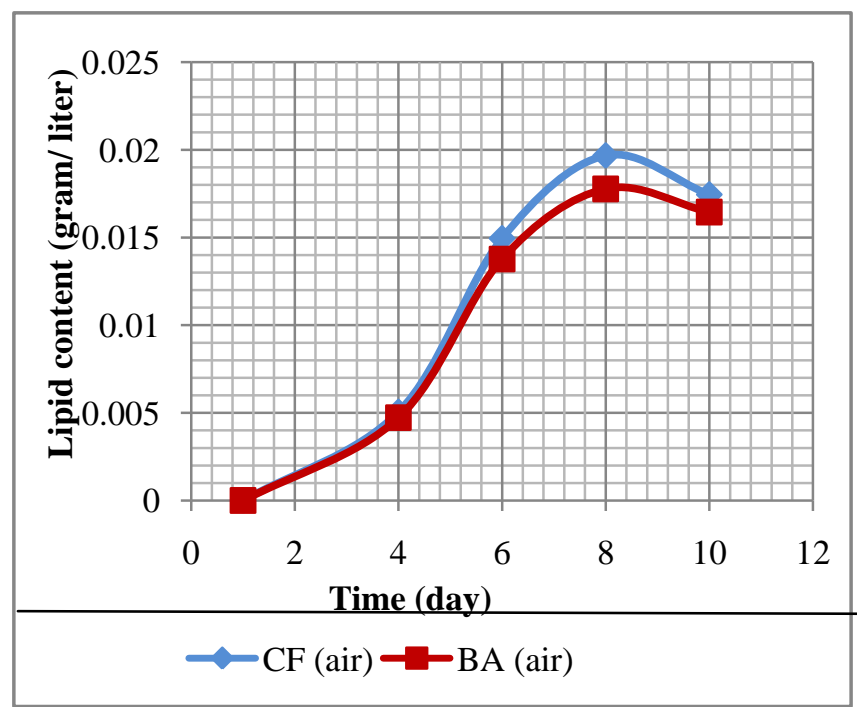

Fig. 4. Lipid content

Although BA has higher yield of biomass than $\mathrm{CF}$, the yield of lipid content is lower than CF. The shape of the chart is almost the same and the difference is not so much. It means 
that the local isolated microalgae have a potential in lipid production.

\section{REFERENCE}

[1] M. M. Phukan, R. S. Chutia, B. K. Konwar, and R. Kataki, "Microalgae Chlorella as a potential bio-energy feedstock," Applied Energy, Elsevier, November 2010.

[2] J. A. V. Costa and M. G. D. Morais, "The role of biochemical engineering in the production of biofuels from microalgae," Bioresource Technology, Elsevier, vol. 102, pp. 2-9, June 2010.

[3] S. Amin, "Review on biofuel oil and gas production processes from microalgae," Energy Conversion and Management, Elsevier, vol. 50, pp. 1834-1840, April 2009.

[4] H. Fukuda, A. Kond, and H. Noda, "Biodiesel Fuel Production by Transesterification of Oils," Bioscience and Bioengineering, vol. 92, pp. 405-416, September 2001.

[5] W. Zhou, Y. Li, M. Min, B. Hu, P. Chen, and R. Ruan, "Local bioprospecting for high-lipid producing microalgal strains to be grown on concentrated municipal wastewater for biofuel production," Bioresource Technology, Elsevier, vol. 102, pp. 6909-6919, April 2011.

[6] B. J. Krohn, C. V. McNeff, B. Yan, and D. Nowlan, "Production of algae-based biodiesel using the continuous catalytic Mcgyan process," Bioresource Technology, Elsevier, vol. 102, pp. 94-100, June 2010.

[7] E. Suali and R. Sarbatly, "Conversion of microalgae to biofuel," Renewable and Sustainable Energy Reviews, Elsevier, vol. 16, pp. 4316-4342, May 2012.

[8] J. D. Wehr and R. G. Sheath, Fresh water algae of North America Ecology and Classification, UK, 2003.

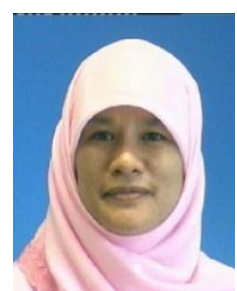

Nurlidia Mansor is a lecturer at Chemical Engineering Department, Universiti Teknologi PETRONAS. She has a degree in Biotechnology and MSc in Environmental Engineering from Universiti Putra Malaysia. Dr. Mansor received her $\mathrm{PhD}$ in Environmental Chemistry from the University of Glasgow, UK. Her area of interest includes Biomonitoring, Bio and Phytoremediation, Microalgae in Biofuel Production and Natural Products in Agriculture Technology.

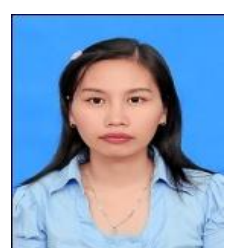

Lam Duong Bich Ngoc was born on 19th January 1987, Kien Giang province, Vietnam. Bachelor of Engineering in Chemical Engineering at Ho Chi Minh City University of Technology, Ho Chi Minh city, Vietnam, 2010. Now MSc student in Chemical Engineering of Universiti Teknologi PETRONAS

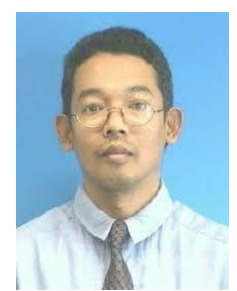

Shuhaimi Mahadzir is an associate professor at Chemical Engineering Department, Universiti Teknologi PETRONAS. He has a Chemical Engineering Degree from University of Tennessee, USA and MSc in Process Integration from UMIST, UK. Dr. Mahadzir received his $\mathrm{PhD}$ in Chemical Engineering from the University of Manchaster. His area of specialization includes Process Operations, Design, Integration and Optimization. He is currently working withthe Process Development Research Group at UTP. 